\title{
The Clinical Profile, Wound Dressings, and Clinical Outcomes of In-patients with Pressure Ulcers at a Tertiary Hospital in the Philippines: A Seven-year Retrospective Study
}

\author{
Jay-V James G. Barit, MD, Shahara Abalos-Babaran, MD, Sarah Faye V. Obbus, MD and Belen L. Dofitas, MD
}

Department of Dermatology, Philippine General Hospital, University of the Philippines Manila

\begin{abstract}
Objectives. Currently, there are no local studies examining wound dressing usage among pressure ulcers in Filipino patients. The study aims to provide preliminary Philippine data among in-patients with pressure ulcers: their demographic characteristics, wound characteristics, wound dressing usage, and associated outcomes per wound dressing.

Methods. A retrospective chart review of patients admitted at the Philippine General Hospital from 2011 to 2017 with a diagnosis of pressure ulcer was conducted.

Results. Eighty-five records were retrieved; $56 \%$ were female and $44 \%$ male, with a mean age of $47.67 \pm 23.03$ years. The mean number of ulcers per patient was $1.65 \pm 1.37$, mostly in Stages 2 and 3, and $90.6 \%$ were in the sacral area. Seventy-three (85.9\%) had utilized at least one form of the wound dressing, mostly plain gauze (83.5\%), usually with silver sulfadiazine or Dakin's solution. Only a smaller subset used silver-impregnated dressings (10.55\%) and hydrocolloid dressings (5.9\%). Comparing advanced versus basic dressings for improved wound outcomes, the crude odds ratio was 3.81 (1.62 - 8.99; $p$-value 0.003 ), which on stratification accounting for bed turning, became 8.92 (1.66 - 47.97; p-value 0.009) for those bed turned and 3.05 (1.01-9.20; p-value 0.075) for those not bed turned.
\end{abstract}

Conclusion. Filipino in-patients with pressure ulcers were similar to those in the literature in terms of the mean number of ulcers and site of involvement. Basic gauze dressings, combined with topical agents, constitute the majority of wound dressing practice. Use of an advanced wound dressing showed a trend favoring improved outcomes, enhanced by pressure redistribution through bed repositioning.

Key Words: Pressure ulcer, wound dressing, retrospective studies

\section{INTRODUCTION}

Pressure ulcers constitute a global healthcare challenge requiring an interdisciplinary approach. ${ }^{1}$ Also referred to as bedsores, decubitus ulcers, pressure sores, and currently as pressure injuries, pressure ulcers are localized skin and underlying soft tissue damage over a bony prominence. They can be related to the use of medical or other devices. These injuries may be on intact skin or be an open ulcer and may be painful. They occur because of sustained, unrelieved, and/or strong pressure, or pressure in combination with shear and/ or friction. ${ }^{1,2}$ The development of pressure ulcers involves the interaction of mechanical forces with tissue tolerance. A pressure gradient, superficial damage from friction, and deeper damage from shear, coupled with varying tolerance of tissues to mechanical loading, all contribute to wound formation. Once set, intrinsic and extrinsic factors affecting 
an individual's tissue tolerance promote pressure ulcer formation. Significant risk factors are mainly categorized into three: impaired mobility or activity, poor perfusion, and skin/pressure ulcer status. Other factors accounted for include skin moisture and nutritional status. ${ }^{1,3}$ In a large inpatient retrospective study extracting administrative data, malnutrition, shock/hypotension, peripheral vascular disease, incontinence, cerebrovascular disease, diabetes mellitus, and fractures were identified as co-morbidities in admitted patients with pressure ulcers, ${ }^{4}$ and these portended a higher risk of pressure ulcer development. In 2016, the terminology has formally shifted from pressure ulcers to pressure injuries and its stages were revised. The establishment of these changes was to be consistent with the current understanding of the etiologies of pressure injuries and to delineate anatomical features in every level of injury. ${ }^{3}$ However, for this study, the term pressure ulcer shall be utilized to conform with the nomenclature commonly used during the period of interest.

The National Pressure Ulcer Advisory Panel (NPUAP) has recently updated the staging of pressure injuries, adapting Arabic instead of Roman numerals, and adding new terminologies: medical device-related pressure injury, and mucosal membrane pressure injury. Medical Device Related Pressure Injuries result from the use of diagnostic or therapeutic devices that produce a pressure injury following the pattern or shape of the device and should be staged similarly to injuries over bony prominences. Mucosal Membrane Pressure Injury is found on mucous membranes related to the use of a medical device but cannot be staged due to mucosal membrane anatomy. In the updated NPUAP staging, Stage 1 is non-blanchable erythema of intact skin, which may be over a bony prominence or due to medical devices. It is differentiated from Deep Tissue Pressure Injury, which is a persistent non-blanchable deep red, purple or maroon discoloration that could be seen in either intact or non-intact skin. Stage 2 describes partial-thickness skin loss with the exposed dermis, with no visible subcutaneous tissue, granulation tissue, slough, or eschar. Stage 3 pressure injury is defined as full-thickness skin loss with granulation tissue, epibole (rolled wound edges), and possible undermining or tunneling. There is no visible fascia, tendon, muscle, ligament, cartilage, or bone; differentiating it from Stage 4 wherein any of the aforementioned tissues may be visualized or directly palpated, hence designated as full-thickness skin and tissue loss. Often stage 4 pressure injuries have epibole, undermining, or tunneling. Both Stage 3 and 4 injuries may have slough or eschar; if they obscure the evaluation of the extent of tissue loss, either stage is classified as Unstageable Pressure Injury. ${ }^{3}$

Pressure ulcer prevention and treatment have a significant socioeconomic burden, which varies per institution and with costs not precisely known ${ }^{1}$ but increases with disease severity. ${ }^{5}$ Patients with pressure ulcers have a lower healthrelated quality of life indices compared to those without ${ }^{6}$ and they can be malodorous, infected, and painful. ${ }^{7}$
Treatment of pressure ulcers has two major strategies: pressure redistribution, usually through support surfaces, and management of the wound environment through wound cleansing, debridement, topical treatments, infection control, and wound dressings. Other management strategies employed in the treatment of pressure ulcers include careful assessment and documentation of the pressure ulcer (including usage of validated tools), nutrition, pain management, pressure redistribution, and other modalities (e.g., biophysical agents such as negative pressure, hyperbaric oxygen, etc.). ${ }^{7,89}$

Wound dressings are primal in pressure ulcer management. They vary on the key material used and additional components. Serving multiple functions, dressings provide padding and protection from friction, pressure, incontinence, or other potential contamination. They help maintain a moist microclimate, either by absorbing excess fluid in wet wounds or by retaining it in dry wounds. This moist environment provides an optimal setting for cellular components of healing, permitting autolytic debridement and facilitating epithelialization rates. Maceration of surrounding skin and a possible predisposition to infection, however, can occur with excess moisture. Features of an ideal dressing include the ability to balance absorption and containment of exudate (allowing moisture but not maceration), thermal insulation, maintenance of an optimal wound $\mathrm{pH}$, permeability to water but not bacteria, protection from particulate contaminants or chemicals, reduction of infection, atraumatic removal, provision of pain relief and comfort, and allowance for frequent dressing changes. ${ }^{17,10}$

There is a multitude of available wound dressings with various functions. Selection is often guided by wound characteristics, cost, and clinical experience. Evidence summaries presently available on wound dressings for pressure ulcer treatment include two earlier systematic reviews, ${ }^{10,11}$ two clinical guidelines, ${ }^{8,12}$ two completed Cochrane reviews, ${ }^{13,14}$ an evidence review article, ${ }^{9}$ and a network meta-analysis. ${ }^{7}$ Current evidence shows that advanced dressings are not conclusively superior to saline gauze. A previous study did not show which dressings will most likely heal pressure ulcers, nor highlighted those that should be evaluated in larger controlled trials. ${ }^{7}$ Usage of a certain dressing seems to rely mainly on clinical opinion, patient preference, and cost. The choice of a particular local application is guided by matching wound bed characteristics and ulcer severity to a dressing that can maintain a moist environment for wound healing. ${ }^{1,710}$ If a certain dressing's use cannot be justified adequately, then the most inexpensive dressing that meets wound needs should be routinely selected. ${ }^{9}$ Despite the lack of robust evidence supporting advanced wound dressings, they remain widely used in the local setting.

Currently, there are no local studies examining wound dressing usage for pressure ulcers among Filipino patients. Published Philippine epidemiologic data is sparse and limited to a prospective cohort study by Molon et al. in 2011 determining pressure ulcer incidence and risk factors 
among hospitalized orthopedic patients. The study also serves as an institutional review of wound dressing practices in patients afflicted with pressure ulcers. Preliminary data from this study may be also useful in developing local wound dressing technologies that may be tailored to the Philippine setting and possibly made more affordable than current commercial products.

\section{METHODS}

This study was a retrospective chart review of patients seen in the Philippine General Hospital admitted from January 2011 to December 2017 with a primary or secondary diagnosis of pressure ulcer, examining pressure ulcer characteristics, wound dressing usage, and wound outcomes following dressing use. Records were obtained based on the Disease Index (a hospital filing system with the International Classification of Diseases (ICD) Codes) with ICD Code L89 - Pressure Ulcer.

The following demographic and clinical information were obtained from the records:

1. Gender

2. Age

3. Length of stay

4. Year admitted

5. Mortality outcomes

6. Ulcer diagnosis (whether pressure ulcer is a primary diagnosis for admission or a secondary diagnosis)

7. Primary service and service/s-in-charge of wound management

8. Presence of co-morbidities (malnutrition, shock/ hypotension, peripheral vascular disease, incontinence, cerebrovascular disease, diabetes mellitus, and fractures)

For each patient with pressure ulcers, the following wound characteristics were recorded:

1. Stage

2. Anatomic location

3. Number

4. Relation to a medical device

5. Presence of a secondary infection

6. Concurrent wound practices (assessment and monitoring of the ulcer, debridement, wound cleansing, topical agents and treatment of infection, pressure redistribution, nutrition, pain management, and others)

For patients with pressure ulcers, the use of wound dressings was determined. The following information for those with wound dressing use was documented:

1. Type of dressing

2. Clinical outcomes

i. Improved outcomes are as follows:

1. Complete Resolution - defined as complete epithelialization of the ulcer with no exudate and no conceivable wound dimensions
2. Partial Improvement - defined as any of the following: a) decrease in any of the wound dimensions, b) decrease of exudation (from heavy to moderate to light to none), c) improvement of tissue type (from necrotic tissue becoming to slough, to granulation tissue, to epithelial tissue and then closed), or d) resolution of secondary infection

ii. Worsened outcomes are as follows:

1. No interval change - no change in previously documented findings in the ulcer

2. Deterioration - defined as a) increase in any of the wound dimensions, $\mathrm{b}$ ) increase in exudation (from no exudate to light, moderate, or severe), c) worsening tissue type, from intact skin to any form of erosion, formation of slough or necrotic tissue) or d) development of a secondary infection

3. Number of days of use

4. Any adverse effects (e.g., maceration, allergic contact dermatitis, etc.)

Standard data collection forms were utilized and data were encoded on Microsoft Excel. The analysis was done using the Statistical Package for the Social Sciences (SPSS) Version 21. Quantitative variables relating to the demographic, pressure ulcer, and wound dressing profiles were expressed in means with standard deviation; qualitative variables expressed in terms of frequencies and percentages. Association for wound outcomes based on utilized dressings was done using Fisher's exact test and odds ratio.

\section{RESULTS}

Based on the ICD-based Disease index filing of the hospital, a total of 295 in-patient charts were filed under the diagnosis of L89 - Pressure Ulcer from 2010 to 2017. Only 3 records were from the year 2010 and all of them were unavailable, thus only the records from 2011 to 2017 were included. One hundred ninety-five charts were excluded because they can no longer be retrieved and were not in the file at the medical records division. A total of 85 charts, all unique patients, were available for retrieval and subsequently reviewed.

\section{Clinical and Demographic Profile of In-Patients with Pressure Ulcers}

Fifty-six percent of the in-patient cases were female and $44 \%$ were male, with a mean age of $47.67 \pm 23.03$ years (ranging from $5-87$ years old). Stratifying by age, the majority of the cases are in the older age group from 50 years onwards. (Table 1) The mean length of stay of these admitted patients is $22.99 \pm 23.18$, ranging from 2 to 152 days, with $65.9 \%(n=56)$ staying for 20 days or less. $54 \%$ of the cases were admitted primarily due to the ulcers and $46 \%$ developed 
Table 1. Frequency distribution of pressure ulcers according to age, year and ulcer characteristics

\section{Characteristics}

\begin{tabular}{crr} 
Age $(\boldsymbol{n}=85)$ & & \\
$0-10$ & 5 & $5.9 \%$ \\
$11-20$ & 12 & $14.1 \%$ \\
$21-30$ & 7 & $8.2 \%$ \\
$31-40$ & 9 & $10.6 \%$ \\
$41-50$ & 9 & $10.6 \%$ \\
$51-60$ & 12 & $14.1 \%$ \\
$61-70$ & 14 & $16.5 \%$ \\
$71-70$ & 14 & $16.5 \%$ \\
$80-100$ & 3 & $3.5 \%$ \\
\hline
\end{tabular}

Year admitted $\left({ }^{*} n=\right.$ Total number of in-patient admissions, excluding rooming-in and neonatal intensive care)

\begin{tabular}{lrr}
$2011(n=41,457)$ & 9 & $0.02 \%$ \\
$2012(n=41,262)$ & 20 & $0.05 \%$ \\
$2013(n=40,712)$ & 7 & $0.02 \%$ \\
$2014(n=40,456)$ & 14 & $0.03 \%$ \\
$2015(n=39,417)$ & 3 & $0.01 \%$ \\
$2016(n=49,985)$ & 16 & $0.03 \%$ \\
2017 ( $n=44,611)$ & 16 & $0.04 \%$ \\
\hline Number of pressure ulcers per patient $(n=85)$ & & \\
1 & 61 & $71.8 \%$ \\
2 & 8 & $9.4 \%$ \\
3 & 9 & $10.6 \%$ \\
4 & 4 & $4.7 \%$ \\
5 & 2 & $2.4 \%$ \\
10 & 1 & $1.2 \%$ \\
\hline Stage of pressure ulcer $(n=85)$ & & \\
1 & 4 & $4.7 \%$ \\
2 & 51 & $60 \%$ \\
3 & 44 & $51.8 \%$ \\
4 & 32 & $37.6 \%$
\end{tabular}

Location of pressure ulcer ( $n=140$, total number of ulcers)

\begin{tabular}{lrr} 
Sacrum & 77 & $90.6 \%$ \\
Gluteal area & 13 & $15.3 \%$ \\
Hip & 14 & $16.5 \%$ \\
Feet & 16 & $18.8 \%$ \\
Lower extremities (excluding feet) & 12 & $14.1 \%$ \\
Upper extremities & 6 & $7.1 \%$ \\
Head & 2 & $2.4 \%$ \\
\hline
\end{tabular}

pressure ulcers during their admission. No mortalities were recorded in this review. Co-morbid that are known intrinsic risk factors for pressure ulcer development, such as shock, cerebrovascular disease, diabetes mellitus, malnutrition, and fractures have been found in 28\%, 23\%, 22\%, 18\%, and $10 \%$ of cases respectively. Sixty percent of cases were managed by the Internal Medicine service, followed by pediatrics (15.3\%). The Internal Medicine and Plastic Surgery services were the most commonly involved in wound care at $49.4 \%$ and $28.2 \%$, respectively. The frequency was very low, ranging from $0.01 \%$ to $0.05 \%$ per year from 2011 to 2017. (Table 1 )
Table 2. Frequency of Concurrent Treatment Practices $(n=85)$

\begin{tabular}{lrr}
\multicolumn{1}{c}{ Other Concurrent Wound Practices } & Number & Frequency \\
Debridement & & \\
$\quad$ Surgical debridement & 11 & $12.9 \%$ \\
\hline Wound Cleansing & 42 & $49.4 \%$ \\
$\quad$ Dakin's Solution & 7 & $8.2 \%$ \\
Normal saline solution & 1 & $1.2 \%$ \\
Betaine-polyhexanide & 1 & $1.2 \%$ \\
Soap / tap water & 40 & $47.1 \%$ \\
\hline Treatment of Infection and Other Topical Therapies & $34.1 \%$ \\
Silver sulfadiazine & 29 & $17.6 \%$ \\
Intravenous antibiotics & 15 & $4.7 \%$ \\
Zinc oxide/calamine & 4 & $1.2 \%$ \\
MEBO ointment & 1 & $4.7 \%$ \\
Retapamulin & 4 & \\
Mupirocin & & \\
\hline Pressure Redistribution & 36 & $42.4 \%$ \\
Bed turning every 2 hours & 8 & $9.4 \%$ \\
Eggcrate mattress & 11 & $12.9 \%$ \\
\hline Nutrition & 6 & $7.1 \%$ \\
\hline Pain Management & & \\
\hline MEBO - Moist Exposed Burn Ointment & & \\
& &
\end{tabular}

The total number of pressure ulcers in the review was 140 , and the mean number of pressure ulcers per patient was 1.65 \pm 1.37 . The majority of patients $(71.8 \%)$ had only one ulcer during admission, while the maximum number of pressure ulcers recorded in a patient was 10. Most of the documented ulcers are in Stages $2(60 \%)$ and $3(51.8 \%)$, and $90.6 \%$ of the ulcers were located in the sacral area. None of the cases were related to any medical device. Sixty percent $(n=59)$ of the pressure ulcers had no secondary infection; while $31 \%$ $(\mathrm{n}=26)$ had a secondary infection, with $E$. coli, P. mirabilis, and $S$. aureus as the most common isolates.

Table 2 summarizes other concurrent wound practices utilized during their admission, with pressure redistribution, wound cleansing, and infection control as the more commonly employed interventions.

\section{Wound Dressing Usage and Clinical Outcomes}

Among the 85 in-patients with pressure ulcers, 73 (85.9\%) had utilized at least one form of the wound dressing, while 12 (14.1\%) did not mention any dressing use. Among those who used wound dressings, the majority $(n=73)$ have used plain gauze (83.5\%). The majority usually utilized a cleansing agent or topical medication and gauze, most commonly silver sulfadiazine and Dakin's solution. Only a smaller subset has used advanced wound dressings: silverimpregnated dressings (10.55\%) and hydrocolloid dressings (5.9\%). (Table 3) No adverse effects, such as maceration or contact dermatitis, were documented in the charts. Both plain gauze dressings and advanced wound dressings were utilized for an average of 18 days. 
For sacral ulcers, plain gauze with Dakin's solution is utilized in $50.6 \%$ of pressure ulcers. For Stages 3 and 4, Dakin's solution with gauze was frequently used; while plain gauze with silver sulfadiazine was mostly utilized in Stage 2 to 3 ulcers. Advanced dressings were used mostly in Stage 4 cases. Tables 4 and 5 summarize the frequency of wound dressing usage based on anatomic location and stage.

For the outcomes of the pressure ulcers based on dressings utilized, data were clustered based on the following: advanced (specialized) dressings versus basic

Table 3. Frequency of Dressing Usage among In-Patients with Pressure Ulcers

\begin{tabular}{lcc}
\hline \multicolumn{1}{c}{ Dressing } & Number & Frequency \\
No Dressing & 12 & $14.1 \%$ \\
\hline With Dressing & 73 & $85.9 \%$ \\
\hline Gauze & 71 & $83.5 \%$ \\
Gauze + Dakin's solution & 20 & $23.5 \%$ \\
Gauze + Silver sulfadiazine & 42 & $49.4 \%$ \\
Gauze + Zinc oxide/calamine & 4 & $4.7 \%$ \\
Gauze + MEBO ointment & 3 & $3.5 \%$ \\
Gauze + Mupirocin ointment & 3 & $3.5 \%$ \\
Gauze + Plain normal saline solution & 1 & $1.2 \%$ \\
\hline Silver Impregnated (Acticoat) & 6 & $7.05 \%$ \\
\hline Silver Impregnated (Aquacel Ag) & 3 & $3.5 \%$ \\
\hline Hydrocolloid (Duoderm) & 5 & $5.9 \%$ \\
\hline
\end{tabular}

(all gauze dressings), antimicrobial (all silver-impregnated dressings) versus non-antimicrobial (gauze dressings plus hydrocolloid dressings), and hydrocolloid dressings versus non-hydrocolloid dressings (all gauze dressings plus silverimpregnated dressings). Crude odds ratios and a post-hoc stratified analysis according to the presence of pressure redistribution (a major factor affecting pressure ulcer healing) were computed and summarized in Table 6.

\section{DISCUSSION}

The frequency of documented pressure ulcers in this study was higher in older populations, consistent with its increasing occurrence with age. ${ }^{4}$ The patients in this study were relatively younger (47.67 years) compared to the globally reported International Pressure Ulcer Prevalence (IPUP) survey (65.3 years) $)^{15}$ and were predominantly female. In general, other studies observed increased risk in male patients, but conclusions have been inconsistent. ${ }^{4}$ The mean length of stay in this review was much longer at 23 days than the average length of stay between 10.2 to 14.1 days $^{10}$ and greater than 14 days as determined in the study by Molon et al. in the same institution. ${ }^{16}$ Other findings, such as the mean number of pressure ulcers per patient at 1.65 , located mostly in the sacral region, are consistent with current literature. ${ }^{4,15}$ The average number of pressure ulcers in the latest IPUP survey ranged from 1.7 to $1.8 .{ }^{15}$ The sacral area is rendered

Table 4. Frequency of Wound Dressing Usage based on Anatomic Location of the Pressure Ulcer

\begin{tabular}{|c|c|c|c|c|c|c|c|}
\hline \multirow[b]{2}{*}{ Type of Dressing } & \multicolumn{7}{|c|}{ Anatomic Location } \\
\hline & $\begin{array}{c}\text { Sacrum } \\
\mathrm{n}=77\end{array}$ & $\begin{array}{c}\text { Gluteal } \\
\mathrm{n}=19\end{array}$ & $\begin{array}{c}\text { Hip } \\
\text { =14 }\end{array}$ & $\begin{array}{l}\text { Feet } \\
\mathrm{n}=15\end{array}$ & $\begin{array}{c}\text { Lower Extremity } \\
n=23\end{array}$ & $\begin{array}{c}\text { Upper Extremity } \\
n=4\end{array}$ & $\begin{array}{c}\text { Head } \\
n=6\end{array}$ \\
\hline Gauze + Dakin's & 17 (22.1\%) & $6(31.6 \%)$ & $5(35.7 \%)$ & $11(73.3 \%)$ & $11(47.8 \%)$ & $0(0 \%)$ & $0(0 \%)$ \\
\hline Gauze + Silver sulfadiazine & 39 (50.6\%) & $6(31.6 \%)$ & $5(35.7 \%)$ & $3(20 \%)$ & 2 (8.7\%) & $2(50 \%)$ & $0(0 \%)$ \\
\hline Gauze + Zinc Oxide & $4(5.2 \%)$ & 0 (0\%) & 0 (0\%) & $0(0 \%)$ & $0(0 \%)$ & $0(0 \%)$ & $0(0 \%)$ \\
\hline Gauze + MEBO & $3(3.9 \%)$ & $0(0 \%)$ & $0(0 \%)$ & $0(0 \%)$ & $0(0 \%)$ & $0(0 \%)$ & $0(0 \%)$ \\
\hline Gauze + Mupirocin & $3(3.9 \%)$ & $0(0 \%)$ & $0(0 \%)$ & $0(0 \%)$ & $0(0 \%)$ & $0(0 \%)$ & $0(0 \%)$ \\
\hline Gauze + normal saline & $0(0 \%)$ & $0(0 \%)$ & $1(7.1 \%)$ & $0(0 \%)$ & $0(0 \%)$ & $1(25 \%)$ & 2 (33.3\%) \\
\hline Silver Impregnated (Acticoat) & $3(3.9 \%)$ & $3(15.8 \%)$ & $1(7.1 \%)$ & $1(6.7 \%)$ & $8(34.8 \%)$ & $0(0 \%)$ & $0(0 \%)$ \\
\hline Silver Impregnated (Aquacel Ag) & $5(6.5 \%)$ & $2(10.5 \%)$ & $0(0 \%)$ & $0(0 \%)$ & $0(0 \%)$ & $0(0 \%)$ & $2(33.3 \%)$ \\
\hline Hydrocolloid (Duoderm) & $3(3.9 \%)$ & 2 (10.5\%) & 2 (14.3\%) & $0(0 \%)$ & $2(8.7 \%)$ & $1(25 \%)$ & $2(33.3 \%)$ \\
\hline
\end{tabular}

Table 5. Frequency of Wound Dressing Usage based on Stage of Pressure Ulcer

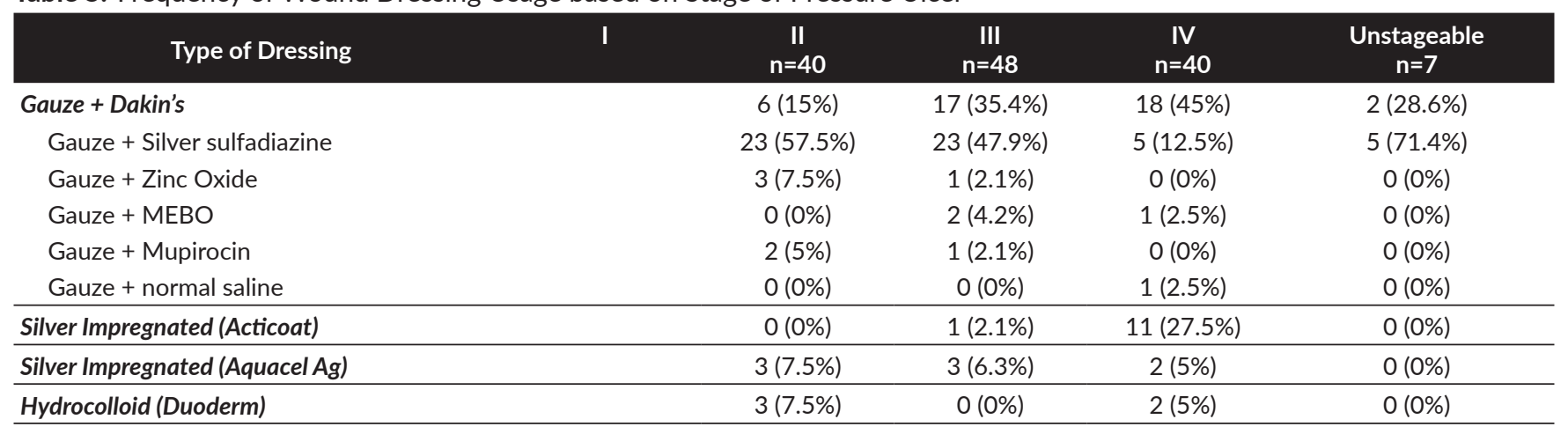


Table 6. Association of pressure ulcer outcomes with kind of dressing, with stratification according to the presence of pressure redistribution

\begin{tabular}{|c|c|c|c|c|c|c|}
\hline & \multirow{2}{*}{$\begin{array}{l}\text { Crude Odds Ratio } \\
(95 \% \mathrm{Cl})\end{array}$} & \multirow{2}{*}{ p value ${ }^{a}$} & Odds Ratio & p value $^{a}$ & Odds Ratio & p value $^{\text {a }}$ \\
\hline & & & \multicolumn{2}{|c|}{ With pressure redistribution } & \multicolumn{2}{|c|}{ Without pressure redistribution } \\
\hline Advanced vs Basic Dressing & $3.81(1.62,8.99)$ & 0.003 & $8.92(1.66-47.97)$ & 0.009 & $3.05(1.01-9.20)$ & 0.075 \\
\hline Antimicrobial vs Non-Antimicrobial & $3.07(1.26,7.47)$ & 0.153 & $15(1.68$ - 133.93) & 0.005 & $2.01(0.64-6.24)$ & 0.239 \\
\hline $\begin{array}{l}\text { Hydrocolloid dressings vs } \\
\text { Non-hydrocolloid dressing }\end{array}$ & $19.88(2.39,165.24)$ & 0.001 & $8.92(1.66-47.97)$ & 0.009 & $41.73(4.78-364.12)$ & 0.000 \\
\hline
\end{tabular}

a Using chi-square test

vulnerable due to the combination of excessive moisture, plus friction and shear, particularly to bedbound patients. ${ }^{4}$ There were no Stage 1 ulcers documented in this study; most were Stages 2 and 3. In the IPUP survey, the most commonly reported ulcers were at Stages 1 and 2 and typically involved non-surgical management. ${ }^{15}$

In this retrospective chart review, the majority used plain gauze mostly combined with topicals, such as silver sulfadiazine and Dakin's solution, most probably because these are considered inexpensive options. However, a review by Boyko et al. showed that gauze dressings are frequently changed and maybe more expensive due to other incurred expenses. ${ }^{17}$ In a study comparing occlusive versus gauze dressings, associated nursing costs were significantly higher in gauze dressings compared to occlusive dressings. ${ }^{18}$ Dakin's solution was mostly used in higher pressure ulcer stages; and at 10-fold dilution, it retained its antimicrobial properties without adversely affecting the normal healing process. ${ }^{19}$ Silver sulfadiazine was also widely utilized in combination with gauze; however, as included in a recent review of antiseptics for pressure ulcers, any particular antimicrobial treatment had no consistent evidence of benefit. ${ }^{20}$ In one study included in the review, silver sulfadiazine had higher costs compared to silver-impregnated dressings. For burn wounds, other alternative therapies are superior in another meta-analysis. ${ }^{21}$ Silver sulfadiazine was also demonstrated to impair re-epithelialization more compared to nanosilver in a study comparing conjugated silver dressings. ${ }^{22}$

The results show, albeit from a small sample size, a trend for advanced wound dressings to have betterwound outcomes compared to basic wound dressings. The initial Cochrane network meta-analysis did not show the superiority of advanced wound dressings to saline gauze. ${ }^{7}$ A more recent network meta-analysis however showed that advanced dressings were better than basic gauze, with foam, active and hydroactive dressings faring better but did not reach statistical significance. ${ }^{23}$ For hydrocolloid dressings, the magnitude of benefit is large but very imprecise, likely an effect of the very limited sample size. When post-hoc analysis stratifying according to the presence of pressure redistribution was done, repositioning improved outcomes except for a peculiar and unsound result in hydrocolloid dressings, wherein improved outcomes were of greater magnitude with those who were not repositioned from the very few patients using those dressings. In general, repositioning is crucial to the management and is always recommended if possible. ${ }^{8}$ Hydrocolloid dressings, suited for wounds with minimal to moderate drainages such as Stage 2 and 3 ulcers $;{ }^{17}$ the use in the study was seen in Stages 2 and 4. Results on silvercontaining dressings, which were clustered as antimicrobial in this study, did not show statistical significance except when stratified to include pressure redistribution but with imprecise estimates. In general, silver dressings should be discontinued after clearance of infection as it can impair wound healing due to keratinocyte and fibroblast toxicity, ${ }^{17}$ but it was not possible to determine in this study whether the use of silver dressings was discontinued after the infection resolved. Silver nanoparticles in wound dressings however have shown to result in faster healing compared to silver sulfadiazine, ${ }^{22}$ supporting the value of silver-impregnated dressings in current practice.

The major limitation of this study is its small sample size. Missing data, improper or incorrect coding, or poor documentation are limitations present in chart review and may affect the quality of data retrieved. Costing, which is an important parameter evaluated in studies examining wound dressing usage, could not be computed due to the nature of billing and recording in the institution reviewed. Medicines are usually bought by the patient outside the hospital and an itemized billing is not included in the physical medical records of patients. The records were physical charts and not encoded on an electronic medical system; documentation of pressure ulcer evaluation and management is not standardized.

\section{CONCLUSION}

This single-institution review of wound dressings for pressure ulcers showed that the clinical characteristics of Filipino in-patients were similar to previous studies with larger populations in terms of the mean number of ulcers and sites of involvement. Basic gauze dressings, combined with topical agents, constitute the majority of wound dressing used for pressure ulcers. The practice of using Dakin's solution with plain gauze can still be considered of value, while the common practice of silver sulfadiazine with gauze may be reevaluated.

Collectively, the use of an advanced wound dressing showed a trend favoring improved outcomes, which 
was enhanced by pressure redistribution through bed repositioning. Silver-containing dressings have an uncertain significant benefit but are promising in terms of antimicrobial control while promoting wound healing. Limitations include a small sample size, unavailability of costing data, and the physical nature of records. Multicenter reviews and additional controlled trials comparing dressings should be sought to improve the quality of evidence. The development of a more cost-efficient, locally available advanced wound dressing, particularly a silver-containing dressing, may be of benefit in the local setting.

\section{Disclaimer}

The views expressed in this article are the authors' own and do not reflect the views of the institution.

\section{Statement of Authorship}

All authors participated in data collection and analysis, and approved the final version submitted.

\section{Author Disclosure}

All authors declared no conflicts of interest.

\section{Funding Source}

This paper was self-funded.

\section{REFERENCES}

1. Ayello EA, Baranoski S, Cuddigan JE., Harris WS. Pressure ulcers. In: Baranoski S, Ayello EA, eds. Wound care essentials: Practice principles, 4th ed. Philadelphia: Wolters Kluwer; 2016. pp. 309-39.

2. Edsberg LE, Black JM, Goldberg M, McNichol L, Moore L, Sieggreen M. Revised National Pressure Ulcer Advisory Panel pressure injury staging system: Revised pressure injury staging system. J Wound Ostomy Continence Nurs. 2016 Nov/Dec;43(6):585-597. doi: 10.1097/WON.0000000000000281.

3. Coleman S, Gorecki C, Nelson EA, Closs SJ, Defloor T, Halfens R, et al. Patient risk factors for pressure ulcer development: systematic review. Int J Nurs Stud. 2013 Jul;50(7):974-1003. doi: 10.1016/ j.ijnurstu.2012.11.019. Epub 2013 Feb 1.

4. Bauer K, Rock K, Nazzal M, Jones O, Qu W. Pressure ulcers in the United States' inpatient population from 2008 to 2012: Results of a retrospective nationwide study. Ostomy Wound Manage. 2016 Nov;62(11):30-8.

5. Dealey C, Posnett J, Walker A. The cost of pressure ulcers in the United Kingdom. J Wound Care. 2012 Jun;21(6):261-2, 264, 266. doi: 10.12968/jowc.2012.21.6.261.

6. Essex HN, Clark M, Sims J, Warriner A, Cullum N. Healthrelated quality of life in hospital inpatients with pressure ulceration: assessment using generic health-related quality of life measures. Wound Repair Regen. 2009 Nov-Dec;17(6):797-805. doi: 10.1111/j.1524475X.2009.00544.x.

7. Westby MJ, Dumville JC, Soares MO, Stubbs N, Norman G. Dressings and topical agents for treating pressure ulcers. Cochrane Database Syst Rev. 2017 Jun 22;6(6):CD011947. doi: 10.1002/14651858. CD011947.pub2.

8. European Pressure Ulcer Advisory Panel (EPUAP) National Pressure Ulcer Advisory Panel (NPUAP), Pan Pacific Pressure Injury Alliance (PPPIA), Prevention and treatment of pressure ulcers: Quick reference guide [Internet]. 2014 [cited 2017 Sept]. Available from: http://www.npuap.org/wp-content/uploads/2014/08/QuickReference-Guide-DIGITAL-NPUAP-EPUAP-PPPIA-Jan2016.pdf.
9. The National Institute for Health and Care Excellence (NICE), Chronic wounds: advanced wound dressings and antimicrobial dressings [Internet]. 2016 [cited 2017 Sept]. Available from: https:// www.nice.org.uk/advice/esmpb2/chapter/key-points-from-theevidence\#.

10. Saha S, Smith MEB, Totten A, Fu R, Wasson N, Rahman B, Motu'apuaka M, et al. Pressure ulcer treatment strategies: Comparative effectiveness [Internet]. Rockville (MD): Agency for Healthcare Research and Quality (US); 2013 May. Report No.: 13-EHC003-EF. PMID: 23785727.

11. Reddy M, Gill SS, Kalkar SR, Wu W, Anderson PJ, Rochon PA. Treatment of pressure ulcers: a systematic review. JAMA. 2008 Dec 10;300(22):2647-62. doi: 10.1001/jama.2008.778.

12. National Institute for Health and Care Excellence, Pressure ulcers: prevention and managements [Internet]. 2016 [cited 2019 Jun]. Available from: https://www.nice.org.uk/guidance/cg179.

13. Dumville JC, Stubbs N, Keogh SJ, Walker RM, Liu Z. Hydrogel dressings for treating pressure ulcers. Cochrane Database Syst Rev. 2015 Feb 17;(2):CD011226. doi: 10.1002/14651858.CD011226. pub2. PMID: 25914909.

14. Dumville JC, Keogh SJ, Liu Z, Stubbs N, Walker RM, Fortnam M. Alginate dressings for treating pressure ulcers. Cochrane Database Syst Rev. 2015 May 21;(5):CD011277. doi: 10.1002/14651858. CD011277.pub2. PMID: 25994366.

15. VanGilder C, Lachenbruch C, Algrim-Boyle C, Meyer S. The International Pressure Ulcer Prevalence ${ }^{\mathrm{TM}}$ Survey: 2006-2015: A 10 -year pressure injury prevalence and demographic trend analysis by care setting. J Wound Ostomy Continence Nurs. 2017 Jan/ Feb;44(1):20-28. doi: 10.1097/WON.0000000000000292.

16. Molon JND, Estrella EP. Pressure ulcer incidence and risk factors among hospitalized orthopedic patients: Results of a prospective cohort study. Ostomy Wound Management. 2011Oct;57(10).

17. Boyko TV, Longaker MT, Yang GP. Review of the current management of pressure ulcers. Adv Wound Care (New Rochelle). 2018 Feb 1;7(2):57-67. doi: 10.1089/wound.2016.0697.

18. Ubbink DT, Vermeulen H, Goossens A, Kelner RB, Schreuder SM, Lubbers MJ. Occlusive vs gauze dressings for local wound care in surgical patients: a randomized clinical trial. Arch Surg. 2008 Oct;143(10):950-5. doi: 10.1001/archsurg.143.10.950.

19. Ueno CM, Mullens CL, Luh JH, Wooden WA. Historical review of Dakin's solution applications. J Plast Reconstr Aesthet Surg. 2018 Sep;71(9):e49-e55. doi: 10.1016/j.bjps.2018.05.023. Epub 2018 Jun 8. PMID: 30173720.

20. Norman G, Dumville JC, Moore ZE, Tanner J, Christie J, Goto S. Antibiotics and antiseptics for pressure ulcers. Cochrane Database Syst Rev. 2016 Apr 4;4(4):CD011586. doi: 10.1002/14651858. CD011586.pub2.

21. Maciel ABDS, Ortiz JF, Siqueira BS, Zanette GF. Tissue healing efficacy in burn patients treated with $1 \%$ silver sulfadiazine versus other treatments: a systematic review and meta-analysis of randomized controlled trials. An Bras Dermatol. 2019 Mar-Apr;94(2): 204-210. doi: 10.1590/abd1806-4841.20198321. Epub 2019 May 9.

22. Mohseni M, Shamloo A, Aghababaie Z, Afjoul H, Abdi S, Moravvej $\mathrm{H}$, et al. A comparative study of wound dressings loaded with silver sulfadiazine and silver nanoparticles: In vitro and in vivo evaluation. Int J Pharm. 2019 Jun 10;564:350-358. doi: 10.1016/j.ijpharm. 2019.04.068. Epub 2019 Apr 24.

23. Furuya-Kanamori L, Walker RM, Gillespie BM, Clark J, Doi SAR, Thalib L. Effectiveness of different topical treatments in the healing of pressure injuries: A network meta-analysis. J Am Med Dir Assoc. 2019 Apr;20(4):399-407. doi: 10.1016/j.jamda.2018.10.010. Epub 2018 Nov 22. 